\title{
Analysis of Factors That Influence the Epidemiology of Sclerotinia minor on Peanut
}

\author{
D. L. Smith and J. E. Hollowell, Department of Plant Pathology, T. G. Isleib, Department of Crop Science, and \\ B. B. Shew, Department of Plant Pathology, North Carolina State University, Raleigh 27695
}

\begin{abstract}
Smith, D. L., Hollowell, J. E., Isleib, T. G., and Shew, B. B. 2006. Analysis of factors that influence the epidemiology of Sclerotinia minor on peanut. Plant Dis. 90:1425-1432.

In North Carolina, sclerotia of Sclerotinia minor germinate myceliogenically to initiate infections on peanut. The effects of soil temperature and soil matric potential $\left(\Psi_{\mathrm{M}}\right)$ on germination and growth of $S$. minor have not been well characterized, and little is known about relative physiological resistance in different parts of the peanut plant. Laboratory tests examined the ability of the fungus to germinate, grow, and infect detached peanut leaflets at soil temperatures ranging from 18 to $30^{\circ} \mathrm{C}$ at $\Psi_{\mathrm{M}}$ of $-100,-10$, and $-7.2 \mathrm{kPa}$. In addition, detached pegs, leaves, main stems, and lateral branches from three peanut lines varying in field resistance were examined for resistance to infection by $S$. minor. Sclerotial germination was greatest at $30^{\circ} \mathrm{C}$ and $\Psi_{\mathrm{M}}$ of $-7.2 \mathrm{kPa}$. Final mycelial diameters decreased with decreasing $\Psi_{\mathrm{M}}$, whereas soil matric potential did not affect lesion development. Mycelial growth and leaflet lesion expansion were maximal at 18 or $22^{\circ} \mathrm{C}$. Soil $\Psi_{\mathrm{M}}$ did not affect leaflet infection and lesion expansion. Lesions were not observed on leaves incubated at temperatures of $29^{\circ} \mathrm{C}$ or above, but developed when temperatures were reduced to 18 or $22^{\circ} \mathrm{C} 2$ days after inoculation. Pegs and leaflets were equally susceptible to infection and were more susceptible than either main stems or lateral branches. Results of this work, particularly the effects of temperature on S. minor, and knowledge of peanut part susceptibility has application in improving Sclerotinia blight prediction models for recommending protective fungicide applications.
\end{abstract}

Additional keywords: Arachis hypogaea, groundnut, Sclerotinia blight

Sclerotinia blight of peanut (Arachis hypogaea) is caused by the soilborne fungus Sclerotinia minor. The first report of this disease in the United States was made in Virginia in 1971 (26). Since then, Sclerotinia blight has become widespread in Virginia and North Carolina, and in parts of Oklahoma and Texas. Losses in North Carolina are an estimated $\$ 1$ to 4 million annually (B. Shew, unpublished data).

Sclerotia of $S$. minor germinate myceliogenically to initiate infections on peanut in mid- to late summer. Favorable conditions for sclerotial germination and infection are reported as temperatures of 17 to $21^{\circ} \mathrm{C}$ and relative humidities of greater than $95 \%$ (25). In addition, soil $\mathrm{pH}$ near 6.5 is favorable for the germination of sclerotia in the field (26). Volatiles emitted from moist, undecomposed plant tissue stimulate sclerotial germination (12). As reported for Sclerotium rolfsii (3), substances stimulatory to germination include alcohols, aldehydes, esters, and halogenated hydrocarbons (12).

Corresponding author: D. L. Smith

E-mail: dlsmith6@unity.ncsu.edu

Accepted for publication 22 June 2006.

DOI: 10.1094/PD-90-1425

(C) 2006 The American Phytopathological Society
Advisories based on weather data have proven successful in managing Sclerotinia blight in Virginia (18). Recommendations for fungicide applications are made after peanut canopy closure (24) and when conditions are favorable for Sclerotinia minor over a period of five consecutive days (18). Although the Virginia advisory model has performed well, further refinements could lead to better application timing for Sclerotinia blight control in North Carolina.

Most of the information available about the effects of temperature and moisture on $S$. minor was derived from tests done on agar culture $(5,34)$. Research dealing directly with soil temperature and moisture effects was conducted in California with soils that differ markedly from those found in peanut-producing areas (10). In those studies, sclerotial germination of lettuce isolates was optimal at approximately $15^{\circ} \mathrm{C}$ in soils with a water potential of $-0.1 \mathrm{MPa}$. Sclerotia rarely germinated carpogenically.

In general, peanuts are very susceptible to Sclerotinia blight, but some moderately resistant Virginia-type cultivars are available. The partially resistant cv. VA 93B was registered in 1994 (8), followed by the partially resistant cvs. VA 98R (22) and Perry (15). Various mechanisms may be responsible for the partial resistance observed in these cultivars. They all have prostrate lateral branches with an erect main stem $(8,15,22)$. Growth habits of this type can act as an avoidance mechanism $(6,7)$. Physiological resistance also may be present in some lines resistant to infection by $S$. minor $(6,14)$. Certain structural and physiological characteristics, including phytoalexin induction, waxy cuticles, and thickened cortical cells contribute to resistance in bean, peanut, and alfalfa $(7,20,27)$.

Evaluations for resistance in peanut to Sclerotinia blight traditionally have been done in field plots with varying levels of disease over many years (7). Field trials, however, do not distinguish between physiological resistance and avoidance (6). Therefore, greenhouse and laboratory screening methods have sought to expedite the selection process and identify the presence of physiological resistance $(4,6,9$, 14,21).

Detached leaflet inoculation has utility for screening large populations for resistance to $S$. minor (14). However, results are only moderately correlated with field trial results. This could be due to differences in crop phenology leading to avoidance, or could indicate that reactions on detached leaves are not representative of reactions of plant parts such as pegs, pods, and lateral branches. Furthermore, it is common for expression of partial resistance to be affected by environmental variables, as demonstrated for resistance to $S$. sclerotiorum in soybean (23).

A better understanding of the biology of both the host and fungus would assist in breeding for resistance, improve the accuracy of disease advisories, and enhance development of disease management. The objective of this project was to evaluate the relative resistance of various peanut plant parts to colonization by $S$. minor, and to determine how field-soil moisture and temperature affect fungal germination, growth, and leaf infection of partially resistant or susceptible peanut lines.

\section{MATERIALS AND METHODS}

Detached part inoculation. Three peanut lines were planted and grown in the greenhouse for 8 to10 weeks before testing. In the first set of two runs (eight replicates per run), lines included the highly susceptible cv. NC 12C, the moderately susceptible cv. NC 7, and GP-NC WS12, a germ plasm line with high levels of partial resistance in field and detached-leaflet evaluations $(14,32)$. In the second set of three runs (eight replicates per run), the lines included $\mathrm{NC} 12 \mathrm{C}$, $\mathrm{NC} 7$, and 
N96076L, an advanced breeding line that exhibited high partial resistance to Sclerotinia blight in the field (16). Seed were pregerminated for 2 to 3 days prior to planting. Two seeds were planted in each $15-\mathrm{cm}$ clay pot containing a $2: 1(\mathrm{vol} / \mathrm{vol})$ mixture of steamed sandy-loam soil and commercially available play sand. Fortyone pots of each line were planted for each run. Plants were fertilized at 42 days after planting (DAP) with $100 \mathrm{ml}$ of a $0.13 \%$ solution of water-soluble 20-20-20 (N-PK) fertilizer. A razor blade was used to detach peanut plant parts on the day of inoculation. Detached parts included a peg (gynophore) that had penetrated the soil surface, a single leaflet still attached to the petiole, the main stem, and two primary lateral branches. The detached parts were brought back to the laboratory and placed in plastic humidity boxes measuring 35 by 27 by $10 \mathrm{~cm}$ deep. The boxes contained a galvanized 6-mm mesh screen placed on top of $825 \mathrm{~cm}^{3}$ of sterile washed sand. The detached plant parts were placed on the screen and inoculated. A 3-mm-diameter agar plug was taken from a 2-day-old culture of an aggressive isolate of $S$. minor grown on potato dextrose agar (PDA; Difco Laboratories, Detroit). The isolate (Shew Laboratory collection P13) originally was obtained from a diseased peanut growing in northeastern North Carolina (14), and was used in all studies. The main stem was inoculated in the center at the second branching node from the bottom of the stem, the peg was inoculated in the center, the leaflet was inoculated along the midrib on the adaxial side, one primary lateral branch was inoculated at a vegetative node, and one primary lateral branch was inoculated at a flowering node. Following inoculation, plant parts were sprayed until droplet formation with a $0.03 \%$ solution of Tween 20 and boxes were closed with a tight-fitting lid. Plant parts were arranged randomly within boxes and boxes were arranged in randomized blocks in a growth chamber at $20^{\circ} \mathrm{C}$ under darkness. The experimental design was a split plot with lines as whole plots and plant parts as subplots. Each day for 7 days, lesion length was measured along the longest axis of each plant part and the proportion of lesion length to the overall length of the plant part was calculated as a measure of severity. Area under the disease progress curve (AUDPC) was calculated from disease variables for each plant part (30).

Establishing soil moisture treatments. Soil from a field used for growing peanut was collected from the Upper Coastal Plains Research Station near Rocky Mount, NC. The soil (Norfolk loamy sand; fine-loamy, kaolinitic, thermic Typic Kandiudults) was air dried, ground, and passed through a sieve (no. 10, 2-mm openings). A 15-bar ceramic soil pressure plate (Soil Moisture Equipment Corporation, Santa Barbara, CA) was used to determine the water holding capacity of the soil at four matric potentials $\left(\Psi_{\mathrm{M}}\right):-30,-100,-300$, and $-1,500 \mathrm{kPa}$. For each $\Psi_{\mathrm{M}}$ measured, five Plexiglas rings filled with soil were placed on the saturated ceramic plate and equilibrated to the desired $\Psi_{M}$ for $24 \mathrm{~h}$. Soil disks were removed from the apparatus and wet weight was obtained. Soil was dried at $105^{\circ} \mathrm{C}$ for $48 \mathrm{~h}$, and dry weight determined. Soil water content at each $\Psi_{\mathrm{M}}$ was determined and fitted to a moisture release curve. To determine the water holding capacity at $\Psi_{\mathrm{M}}$ of $0,-1,-5$, and -10 $\mathrm{kPa}$, soil was placed in 150-ml fritted-glass Büchner funnels. A hanging water column was established to a water reservoir below the funnel to obtain the desired $\Psi_{\mathrm{M}}$. After soil was equilibrated to the desired $\Psi_{\mathrm{M}}$ for $24 \mathrm{~h}$, it was removed from the apparatus and the water content was determined in the same manner as previously described. Using the soil moisture release curve, water content was adjusted to obtain three $\Psi_{\mathrm{M}}$ $(-7.2,-10$, and $-100 \mathrm{kPa})$ for use in experiments. The $\Psi_{\mathrm{M}}$ of $-7.2 \mathrm{kPa}$ represented a $\Psi_{\mathrm{M}}$ near saturation, whereas $-10 \mathrm{kPa}$ represented a $\Psi_{M}$ at field capacity and -100 $\mathrm{kPa}$ represented a $\Psi_{\mathrm{M}}$ where water stress occurred in the sandy soil. For each $\Psi_{\mathrm{M}}, 800 \mathrm{~g}$ of soil was placed in plastic bags, the appropriate volume of water was added, and the soil was allowed to equilibrate for $24 \mathrm{~h}$. Once the soil was adjusted to the desired water content, it was placed in jars $(6 \mathrm{~cm}$ in diameter and $7 \mathrm{~cm}$ in height) to a depth of approximately $2 \mathrm{~cm}$.

Sclerotial germination in soil. Sclerotia were cultured on sterile oat grains (6) and stored at $4^{\circ} \mathrm{C}$ until harvest. Sclerotia with diameters between 1 and $2 \mathrm{~mm}$ were surface disinfested with a $0.03 \% \mathrm{NaOCl}$ solution, dried in a laminar flow hood, and placed in jars (four sclerotia per jar) on the
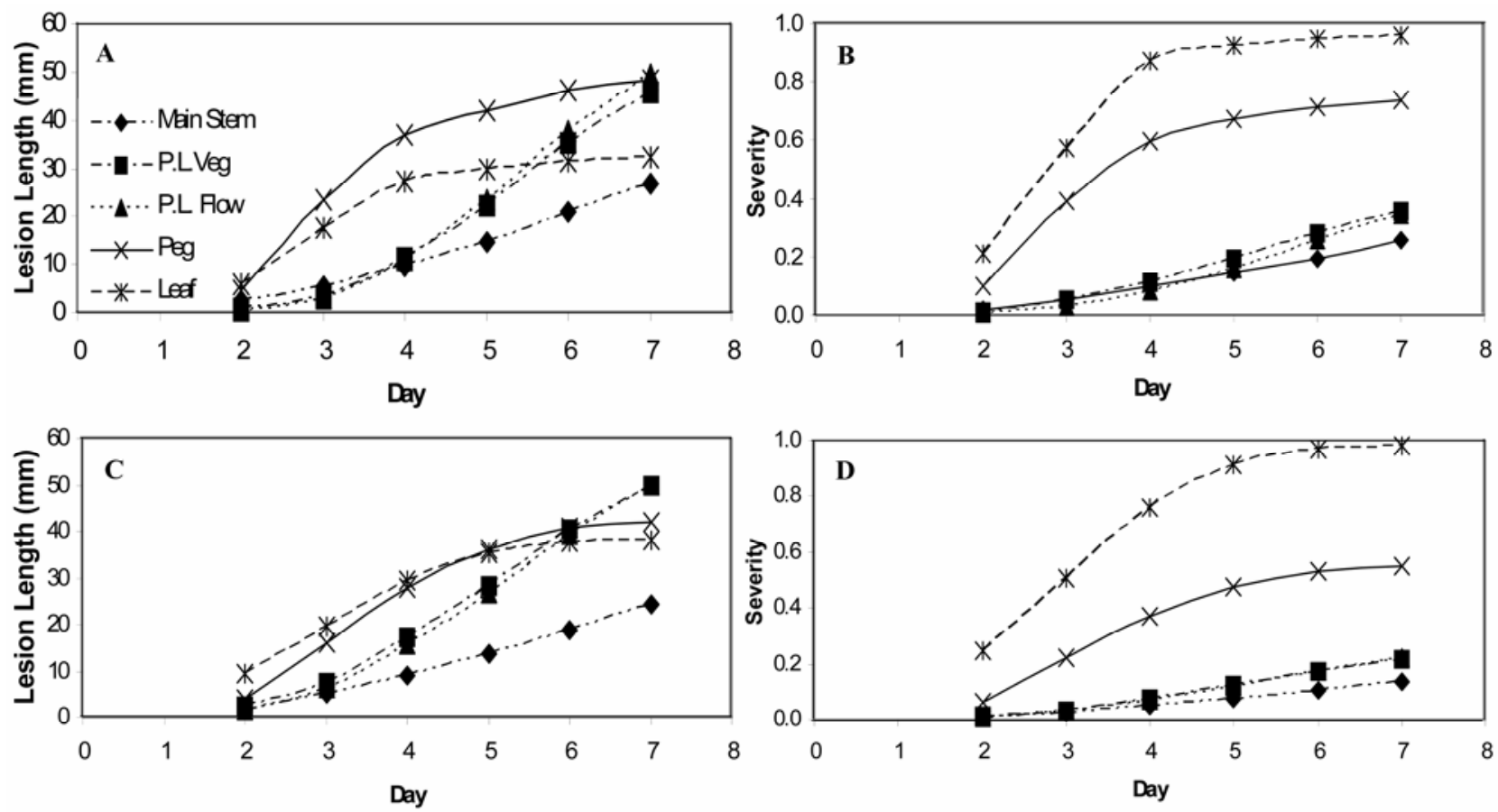

Fig. 1. Lesion length and disease severity on leaflets, main stems, lateral stems, or pegs 7 days after inoculation with Sclerotinia minor. Lateral stems were inoculated at a flowering (P.L. Flow) or vegetative (P.L. Veg) node. A, Average lesion lengths and B, average disease severity (lesion length/plant part length) for runs with the cvs. NC 7 (susceptible) and NC 12C (moderately susceptible) and the breeding line GP-NC WS12 (moderately resistant). C, Average lesion lengths and D, average disease severity (lesion length/plant part length) of parts covered by a lesion for runs with the cvs. NC 7, NC 12C, and N96076L. Cultivar and breeding line susceptibility were the same as in A, except N96076L (resistant) was used in place of GP-NC WS12. 
surface of the soils adjusted to the three $\Psi_{\mathrm{M}}$. Plastic tissue-embedding capsules (size 00; Ted Pella, Inc., Redding, CA) with their lids removed were partially buried in the soil with the top protruding from the soil surface. Approximately $1 \mathrm{ml}$ of histological acetone (JT Baker Chemical Co., Phillipsburg, NJ) was added to the capsules as a germination stimulant. Lids from 6-cm-diameter petri dishes were placed over the openings of the jars and sealed with paraffin film. For this experiment and subsequent studies, jars were placed in small growth chambers (Cchambers) located in the Southeastern Plant Environment Laboratory's Phytotron unit located on the campus of North Carolina State University (33). C-chambers were calibrated to temperatures of $18 \pm$ $0.5,22 \pm 0.5,26 \pm 0.5$, and $30 \pm 0.5^{\circ} \mathrm{C}$ and sclerotia were incubated in darkness for 10 days. Percent germination was determined for sclerotia in each jar. Three jars (observations) were included for each combination of $\Psi_{\mathrm{M}}$ and temperature. The experimental design was a split plot with temperature treatments as whole plots and moisture treatments as subplots. Four replicates were conducted over time. An analysis of variance was conducted using the general linear models procedure (PROC GLM) of SAS (v.8.0; SAS Institute, Cary, NC).

Mycelial expansion on soil. Mycelium was grown on half-strength PDA. The agar medium was made by adding $19.5 \mathrm{~g}$ of dehydrated PDA to 1 liter of deionized water plus $7.5 \mathrm{~g}$ of bacto-agar (Difco Laboratories) and then autoclaved. Two mycelial plugs $(5 \mathrm{~mm}$ in diameter) were taken from 2-day-old cultures and placed on soil adjusted to each of the three $\Psi_{\mathrm{M}}$. Jars were sealed and placed in incubators as described previously and colony diameter measured daily for 6 days. The experimental design was a split plot with temperature treatments as whole plots and moisture treatments as subplots. Two runs with five replicates per run were conducted over time. An analysis of variance was conducted using PROC GLM.

Lesion expansion on leaflets. Leaflets of the second fully expanded leaf on the main stem were detached from plants of NC 12C (susceptible), NC 7 (susceptible), and $\mathrm{N} 96076 \mathrm{~L}$ (resistant). Leaflets were placed individually in jars containing soil at the three water potentials. The abaxial side was touching the soil surface. The adaxial side was inoculated with a mycelial plug (5 $\mathrm{mm}$ in diameter) from a 2-dayold culture of $S$. minor grown on halfstrength PDA. Jars were sealed and placed in incubators at temperatures of 18, 22, 26, and $30^{\circ} \mathrm{C}$ in the dark. Lesion length along the abaxial midrib was measured daily for 7 days. The experimental design was a split plot with temperature treatments as whole plots and moisture treatments as subplots. Two runs (different sets of plants) with three or five replicates per run were conducted over time.

An analysis of variance was conducted using PROC GLM with lesion length as the dependent variable and runs, replicates, moisture, temperature, line, resistance type (susceptible or resistant), time (day after inoculation), and all possible interactions as independent variables. A random statement was included to perform the correct tests of hypothesis using the proper error term for each test. Response surfaces were fitted using untransformed lesion length $(L[T, D])$ data in a modified Gompertz growth function with temperature $(T)$ and time $(D)$ as independent variables $(11,29)$. Briefly, this was a three-step process. First, the asymptote parameter estimates for the modified Gompertz function were determined using the regression procedure (PROC REG SAS, v.8.0) and the third- order polynomial of $T$ with the maximum lesion length $\left(L_{\max }[T]\right)$ for each resistance type at each temperature as follows:

$L_{\max }(T)=\mathrm{a}_{0}+\mathrm{a}_{1} T+\mathrm{a}_{2} T^{2}+\mathrm{a}_{3} T^{3}$

Next, the slope of the line describing lesion length for each day was determined. The slopes were used as the dependent variable $(k[T])$ of the quadratic function of T using PROC REG:

$k(T)=\mathrm{b}_{0}+\mathrm{b}_{1} T+\mathrm{b}_{2} T^{2}$

Finally, the nonlinear regression procedure (PROC NLIN) of SAS (v.8.0) and the estimated parameters as determined by equations 1 and 2 were used to fit the modified Gompertz growth function (29):

$L^{\prime}(T, D)=L_{\max }(T) \exp \{-\exp [-k(T)(D-2)]\} \quad$ (3)

The minimum time period for lesions to develop on leaflets (2 days) was subtracted
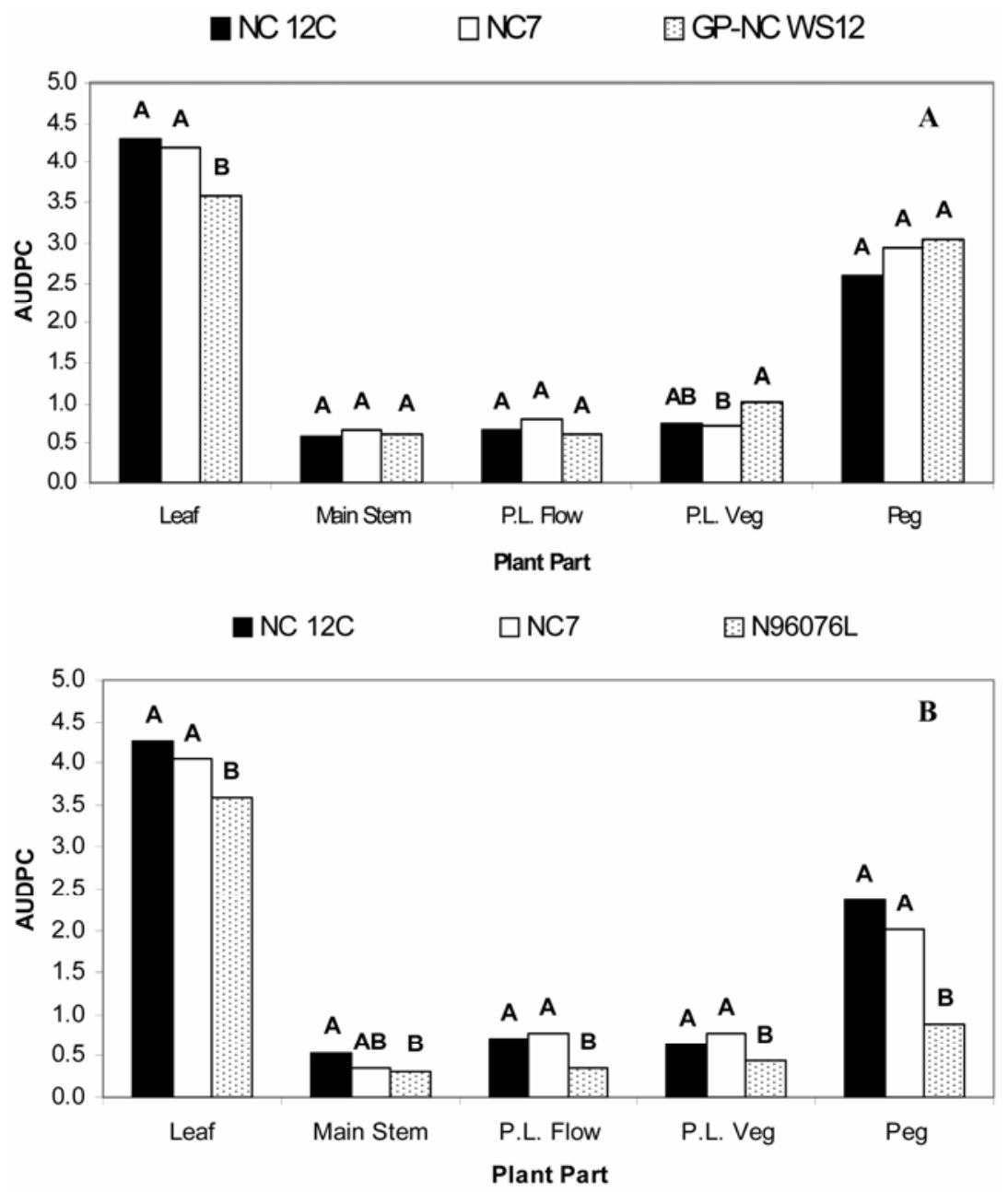

Fig. 2. Area under the disease progress curve (AUDPC) for disease severity on leaflets, main stems, lateral stems, and pegs of two peanut cultivars and two breeding lines inoculated with Sclerotinia minor. Lateral stems were inoculated at a flowering (P.L. Flow) or vegetative (P.L. Veg) node. Values within plant parts with different letters are significantly different according to the Waller-Duncan $k$-ratio $t$ test with $k=$ 100. A, Runs with NC 7 (susceptible), NC 12C (moderately susceptible), and GP-NC WS12 (moderately resistant). For leaf: minimum significant difference $(\mathrm{MSD})=0.35, R^{2}=0.52$, coefficient of variation $(\mathrm{CV})$ $=18.67$. For main stem: $\mathrm{MSD}=0.34, R^{2}=0.42, \mathrm{CV}=83.74$. For P.L. Flow: $\mathrm{MSD}=0.31, R^{2}=0.30, \mathrm{CV}$ $=75.26$. For P.L. Veg: $\mathrm{MSD}=0.26, R^{2}=0.45, \mathrm{CV}=60.79$. For peg: $\mathrm{MSD}=1.28, R^{2}=0.39, \mathrm{CV}=59.41$. $\mathbf{B}$, Cultivars inoculated in this set of runs were the same as in A, except N96076L (moderately resistant) was used in place of GP-NC WS12. For leaf: $\mathrm{MSD}=0.24, R^{2}=0.50, \mathrm{CV}=16.74$. For main stem: $\mathrm{MSD}=$ $0.12, R^{2}=0.54, \mathrm{CV}=95.94$. For P.L. Flow: $\mathrm{MSD}=0.12, R^{2}=0.64, \mathrm{CV}=65.81$. For P.L. Veg: $\mathrm{MSD}=$ $0.13, R^{2}=0.56, \mathrm{CV}=67.82$. For peg: $\mathrm{MSD}=0.59, R^{2}=0.58, \mathrm{CV}=78.76$. 
from $D$ to force the model to begin at the origin as described by Scherm and van Bruggen (29). Evaluation of fit for each of the response surface models was deter-

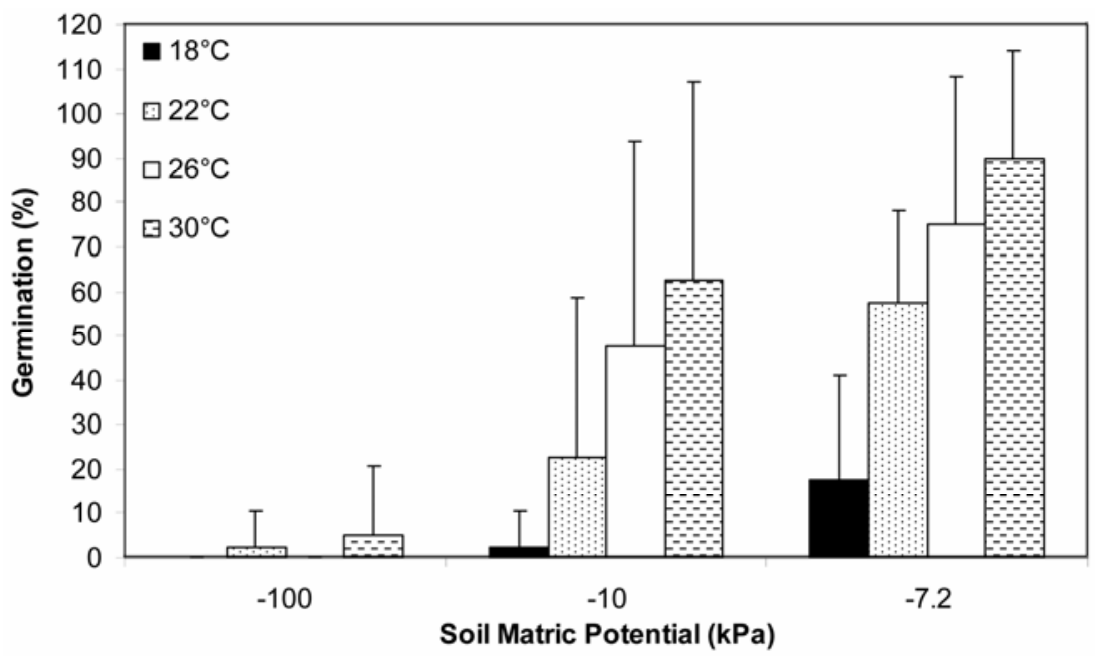

Fig. 3. Percentage of sclerotia of Sclerotinia minor that germinated after incubation for 10 days at three soil matric potentials and four temperatures in the presence of acetone. Sclerotia were produced on sterile oat grains.
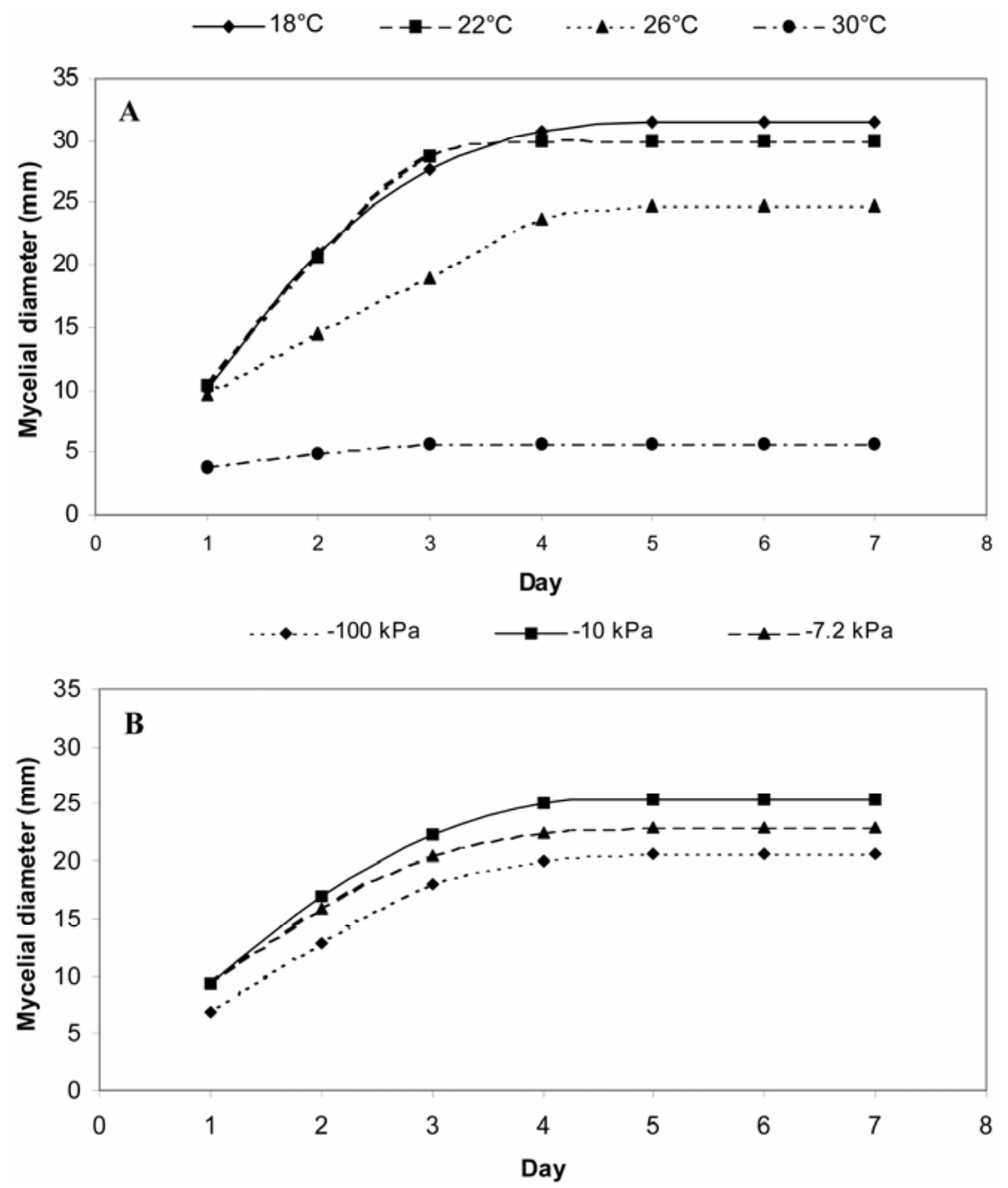

Fig. 4. Effect of soil temperature and matric potential on mycelial expansion by Sclerotinia minor from mycelial plugs taken from cultures grown on half-strength potato dextrose agar. Values were averaged over three matric potentials. A, Soil temperature effect averaged over three soil matric potentials. B, Soil matric potential effect averaged over four soil temperatures.
High temperature threshold for lesion expansion on leaflets. Leaflets were detached from fully expanded compound leaves, placed in jars, and inoculated in the same manner as the previous procedure. Peanut lines used for this experiment included NC 12C (susceptible), Perry (moderately resistant), and N96076L (resistant). The jars were placed in C-chambers (see above) at temperatures of 26, 27, 28, and $29^{\circ} \mathrm{C}$ in the dark. Lesion length along the midrib was measured daily for 6 days. Two runs (different sets of plants) with three or five replicates per run were conducted over time. Analysis was the same as in the previous experiment, with the exception that the cubic term in equation 1 was dropped because of lack of significance, resulting in a quadratic equation.

Effect of temperature change on lesion expansion on leaflets. Leaflets of NC 12C (susceptible), Perry (moderately resistant), and N96076L (resistant) were detached from greenhouse-grown plants, placed on soil in jars, and inoculated using the same procedure as above. The experimental design was a split-split-split plot with initial temperature as whole plots, final temperature as subplot, moisture as sub-subplot, and peanut line as sub-subsubplot. The jars were arranged in incubators at either 28 or $29^{\circ} \mathrm{C}$. After 2 days, half of the jars from each temperature were placed in an incubator at $18^{\circ} \mathrm{C}$, while the remaining jars were placed in an incubator at $22^{\circ} \mathrm{C}$. Lesion length along the midrib was measured for 6 days after inoculation. Two runs (different sets of plants) with three to five replicates per run were conducted over time. An analysis of variance was conducted using PROC GLM with lesion length the dependent variable and runs, replicates, moisture, temperature, line, initial temperature, final temperature, and all possible interactions as independent variables.

\section{RESULTS}

Detached plant-part inoculation. Lesions developed more quickly on leaflets and pegs compared with main stems or lateral branches inoculated at either a vegetative or reproductive node (Fig. 1A and C). Lesions on leaflets and pegs covered most of the leaflet or peg within a few days (Fig. 1B and D). A cultivar-plant part interaction was found in the experiments with GP-NC WS12 $(P=0.0187)$. For these experiments, AUDPCs differed significantly among lines for leaflets and for lateral branches inoculated at a vegetative node, but not pegs, main stems, or lateral branches inoculated at a flowering node (Fig. 2A). Lesions on leaflets of GP-NC WS12 were smaller than those of the other two cultivars. Cultivar main effects were significant for experiments with the breeding line N96076L, but there was a cultivar-plant part interaction in these experiments (Fig. 2B). The AUDPCs of 
N96076L were significantly smaller than those of the other cultivars, but the magnitude of differences was greater on leaves and pegs than on main or lateral stems (Fig. 2B; $P \leq 0.0001$ ).

Sclerotial germination. Soil temperature, $\Psi_{\mathrm{M}}$, and their interaction significantly affected sclerotial germination after 10 days of incubation. Germination was suppressed at $-100 \mathrm{kPa}$, and completely inhibited at 18 and $26^{\circ} \mathrm{C}$ and $-100 \mathrm{kPa}$. Sclerotia germinated at all other temperature and $\Psi_{\mathrm{M}}$ combinations. Maximum germination $(90 \%)$ was recorded at $30^{\circ} \mathrm{C}$ and $\Psi_{\mathrm{M}}$ of $-7.2 \mathrm{kPa}$ (Fig. 3). Germination decreased with decreasing temperature at $\Psi_{\mathrm{M}}$ of -7.2 and $-10 \mathrm{kPa}$ (Fig. 3).

Mycelial expansion on soil. Soil temperature and $\Psi_{\mathrm{M}}$ significantly affected mycelial expansion. Mycelial growth was greatest at 18 and $22^{\circ} \mathrm{C}$ and was greatly inhibited at $30^{\circ} \mathrm{C}$ (Fig. 4A). Temperature effects were consistent across $\Psi_{\mathrm{M}}$ (temperature $-\Psi_{\mathrm{M}}$ was not significant at $P=$ $0.55)$ and colony diameters decreased with decreasing $\Psi_{M}$ (Fig. 4B).

Temperature range for lesion expansion on leaflets. Leaflet lesion expansion was largely dependent on temperature, day after inoculation, and plant line (Table 1). Soil $\Psi_{M}$ main effects and interactions with $\Psi_{\mathrm{M}}$ were not significant; lesions developed at similar rates at all $\Psi_{\mathrm{M}}$ tested. Equations 1, 2, and 3 were used to describe lesion expansion. Equations were developed for susceptible (NC 7 and NC 12C) and resistant (N96076L) leaflets and response surfaces created (Fig. 5A and B) separately based on significant interactions involving temperature, plant line, and day (Table 1). Several interactions of plant line with run also were noted at $P \leq 0.05$, but total contribution of these effects to the overall treatment mean square was small (Table 1). For both resistant and susceptible leaflets, lesion size was greatest at 18 and $22^{\circ} \mathrm{C}$ (Fig. 5A and B). Lesion development was slowed somewhat at $26^{\circ} \mathrm{C}$ (Fig. 5A and $\mathrm{B})$. At $30^{\circ} \mathrm{C}$, no lesions developed, but mycelial growth was observed on the surface of the adaxial side of the leaflet. Rate of lesion expansion typically was greater for susceptible cultivars than for the resistant breeding line. Lesions had nearly covered the leaflets by day 4 for susceptible cultivars (Fig. 5A), whereas it took 5 days for lesions to cover leaflets of the resistant breeding line (Fig. 5B).

High temperature threshold for lesion expansion on leaflets. Lesion expansion on leaflets in response to temperatures near $30^{\circ} \mathrm{C}$ was dependent on temperature, day after inoculation, and plant line (Table 1). Soil $\Psi_{M}$ main effects and most interactions with $\Psi_{\mathrm{M}}$ were not significant; lesions developed at similar rates at all $\Psi_{\mathrm{M}}$ tested (Table 1). The interaction of runtemperature- $\Psi_{\mathrm{M}}$ was significant, in addition to several other interactions with run $(P \leq 0.05)$ that generally contributed little to the overall treatment mean square. Equations 1, 2, and 3 were used to describe leaflet lesion expansion on susceptible and resistant leaflets. For this experiment, significant interactions were found for temperature-day and line-day (Table 1). As before, response surfaces were developed separately for susceptible (NC 12C) and resistant (Perry and N96076L) leaflets (Fig. 5C and D). For both resistant and susceptible leaflets, lesion size was greatest at $26^{\circ} \mathrm{C}$. At $27^{\circ} \mathrm{C}$, lesions were slightly smaller, and lesion development was considerably reduced at $28^{\circ} \mathrm{C}$. Lesion development ceased at $29^{\circ} \mathrm{C}$ (Fig. 5C and D). However, mycelial growth was observed on the surface of the adaxial side of the leaflets subjected to temperatures of $29^{\circ} \mathrm{C}$. As observed in the leaflet lesion expansion studies at 18 to $30^{\circ} \mathrm{C}$, rate of lesion expansion typically was greater for the susceptible cultivar than for the resistant cultivar and breeding line. Lesions had nearly covered leaflets by day 5 or 6 for the susceptible cultivar (Fig. 5C). For the resistant cultivar and breeding line, some healthy leaflet area remained up to 6 days after inoculation (Fig. 5D).

Effect of temperature change on lesion expansion. Initial temperature of incubation significantly affected lesion development (Table 2), with lesions averaging $32 \mathrm{~mm}$ in length 6 days after inocu- lation (4 days after leaflets were moved to final temperatures) when initial temperature was $28^{\circ} \mathrm{C}$ versus $12 \mathrm{~mm}$ when the initial temperature was $29^{\circ} \mathrm{C}$ (Fig. 6). For inoculated leaflets initially exposed to $29^{\circ} \mathrm{C}$, lesion development did not occur until leaflets were moved to 18 or $22^{\circ} \mathrm{C}$. Mycelial growth on the surface of the leaflet was observed at $29^{\circ} \mathrm{C}$ as in previous experiments. Mycelial growth and lesion expansion occurred at $28^{\circ} \mathrm{C}$ and accelerated when leaflets were moved to final temperatures of 18 or $22^{\circ} \mathrm{C}$. Soil $\Psi_{\mathrm{M}}$ main effects were highly significant $(P \leq 0.01)$, with incubation at $\Psi_{\mathrm{M}}$ of $-100 \mathrm{kPa}$ yielding the largest lesions, followed by $\Psi_{\mathrm{M}}$ of -10 and $-7.2 \mathrm{kPa}$ (Fig. 6). Interactions with $\Psi_{\mathrm{M}}$, initial temperature, and run also were significant (Table 2). Inspections of run-initial temperature- $\Psi_{M}$ indicated that the lesion size was greater for run 2 than for run 1 while relative differences among treatments remained as previously described. Main effects of peanut line were highly significant $(P \leq 0.01)$. At an initial temperature of $28^{\circ} \mathrm{C}$, lesion length was relatively uniform across $\Psi_{M}$ (Fig. 6). At an initial temperature of $29^{\circ} \mathrm{C}$, lesion length reflected that of the $\Psi_{\mathrm{M}}$ main effects (Fig. 6). Interactions with peanut line, final temperature, run, and moisture also were significant (Table 2). Lesion lengths were smallest on leaves of the breeding line

Table 1. Mean squares (MS) and $F$ values from analyses of variance for the effects of run (RN), replicate (RP), temperature (T), soil matric potential (M), plant line (L), and time in days after inoculation with Sclerotinia minor (D) on lesion expansion at 18 to $30^{\circ} \mathrm{C}$ and at 26 to $29^{\circ} \mathrm{C}$ (high-temperature threshold) ${ }^{\mathrm{a}}$

\begin{tabular}{|c|c|c|c|c|c|c|}
\hline \multirow[b]{2}{*}{ Source } & \multicolumn{3}{|c|}{ Temperature range study } & \multicolumn{3}{|c|}{ High-temperature threshold study } \\
\hline & df & MS & $F$ value & df & MS & $F$ value \\
\hline RN & 1 & 445 & $0.37 \mathrm{~ns}$ & 1 & 799 & $2.94 \mathrm{~ns}$ \\
\hline $\mathrm{RP}(\mathrm{RN})$ & 6 & 642 & $3.26^{*}$ & 5 & 525 & $1.31 \mathrm{~ns}$ \\
\hline $\mathrm{T}$ & 3 & 71,640 & $100.91 * *$ & 3 & 43,723 & $86.30^{* *}$ \\
\hline $\mathrm{RN} \times \mathrm{T}$ & 3 & 694 & $2.10 \mathrm{~ns}$ & 3 & 506 & $0.61 \mathrm{~ns}$ \\
\hline M & 2 & 130 & $1.29 \mathrm{~ns}$ & 2 & 81 & $0.33 \mathrm{~ns}$ \\
\hline $\mathrm{RN} \times \mathrm{M}$ & 2 & 100 & $0.85 \mathrm{~ns}$ & 2 & 249 & $0.53 \mathrm{~ns}$ \\
\hline $\mathrm{T} \times \mathrm{M}$ & 6 & 34 & $1.07 \mathrm{~ns}$ & 6 & 85 & $0.17 \mathrm{~ns}$ \\
\hline $\mathrm{RN} \times \mathrm{T} \times \mathrm{M}$ & 6 & 33 & $0.77 \mathrm{~ns}$ & 6 & 489 & $3.00 *$ \\
\hline $\mathrm{L}$ & 2 & 1,643 & $4.95 \mathrm{~ns}$ & 2 & 1,790 & $14.34 \mathrm{~ns}$ \\
\hline $\mathrm{RN} \times \mathrm{L}$ & 2 & 331 & $1.25 \mathrm{~ns}$ & 2 & 125 & $0.57 \mathrm{~ns}$ \\
\hline $\mathrm{T} \times \mathrm{L}$ & 6 & 237 & $1.30 \mathrm{~ns}$ & 6 & 344 & $1.44 \mathrm{~ns}$ \\
\hline $\mathrm{RN} \times \mathrm{T} \times \mathrm{L}$ & 6 & 181 & $3.79 *$ & 6 & 239 & $1.51 \mathrm{~ns}$ \\
\hline $\mathrm{M} \times \mathrm{L}$ & 4 & 91 & $0.70 \mathrm{~ns}$ & 4 & 114 & $0.82 \mathrm{~ns}$ \\
\hline $\mathrm{RN} \times \mathrm{M} \times \mathrm{L}$ & 4 & 129 & $2.79 \mathrm{~ns}$ & 4 & 139 & $0.99 \mathrm{~ns}$ \\
\hline $\mathrm{T} \times \mathrm{M} \times \mathrm{L}$ & 12 & 55 & $1.30 \mathrm{~ns}$ & 12 & 165 & $1.23 \mathrm{~ns}$ \\
\hline $\mathrm{RN} \times \mathrm{T} \times \mathrm{M} \times \mathrm{L}$ & 12 & 44 & $0.49 \mathrm{~ns}$ & 12 & 134 & $0.86 \mathrm{~ns}$ \\
\hline $\mathrm{D}$ & 6 & 18,530 & $173.12 * *$ & 5 & 15,769 & $842.10 \mathrm{~ns}$ \\
\hline $\mathrm{T} \times \mathrm{D}$ & 18 & 2,173 & $20.25^{* *}$ & 15 & 2,674 & $40.81 * *$ \\
\hline $\mathrm{RN} \times \mathrm{T} \times \mathrm{D}$ & 18 & 107 & $9.40 * *$ & 15 & 66 & $1.00 \mathrm{~ns}$ \\
\hline $\mathrm{M} \times \mathrm{D}$ & 12 & 6 & $0.71 \mathrm{~ns}$ & 10 & 6 & $0.31 \mathrm{~ns}$ \\
\hline $\mathrm{L} \times \mathrm{D}$ & 12 & 108 & $7.98 * *$ & 10 & 137 & $7.78 * *$ \\
\hline $\mathrm{RN} \times \mathrm{M} \times \mathrm{D}$ & 12 & 8 & $0.90 \mathrm{~ns}$ & 10 & 20 & $0.42 \mathrm{~ns}$ \\
\hline $\mathrm{T} \times \mathrm{M} \times \mathrm{D}$ & 36 & 11 & $1.68 \mathrm{~ns}$ & 30 & 20 & $0.50 \mathrm{~ns}$ \\
\hline $\mathrm{RN} \times \mathrm{L} \times \mathrm{D}$ & 12 & 13 & $0.85 \mathrm{~ns}$ & 10 & 18 & $0.41 \mathrm{~ns}$ \\
\hline $\mathrm{T} \times \mathrm{L} \times \mathrm{D}$ & 36 & 25 & $1.96^{*}$ & 30 & 37 & $1.00 \mathrm{~ns}$ \\
\hline $\mathrm{M} \times \mathrm{L} \times \mathrm{D}$ & 24 & 8 & $0.78 \mathrm{~ns}$ & 20 & 23 & $1.22 \mathrm{~ns}$ \\
\hline $\mathrm{RN} \times \mathrm{T} \times \mathrm{M} \times \mathrm{D}$ & 36 & 7 & $0.83 \mathrm{~ns}$ & 30 & 41 & $3.24 * *$ \\
\hline $\mathrm{RN} \times \mathrm{T} \times \mathrm{L} \times \mathrm{D}$ & 36 & 13 & $1.59 *$ & 30 & 37 & $2.94 * *$ \\
\hline $\mathrm{RN} \times \mathrm{M} \times \mathrm{L} \times \mathrm{D}$ & 24 & 11 & $1.38 \mathrm{~ns}$ & 20 & 19 & $1.49 \mathrm{~ns}$ \\
\hline $\mathrm{T} \times \mathrm{M} \times \mathrm{L} \times \mathrm{D}$ & 72 & 8 & $1.05 \mathrm{~ns}$ & 60 & 20 & $1.56^{*}$ \\
\hline
\end{tabular}

a $F$ values: $* *=$ significance at the $P \leq 0.01$ level; $*=$ significance at the $P \leq 0.05$ level; and ns $=$ not significant at the $P \leq 0.05$ level. 
$\mathrm{N} 96076 \mathrm{~L}$, except at $-100 \mathrm{kPa} \Psi_{\mathrm{M}}$ in run 2, where lesion lengths did not differ among lines. When final temperature was $18^{\circ} \mathrm{C}$, lesions were larger on cv. Perry than on other lines; whereas, at $22^{\circ} \mathrm{C}$, lesions on leaflets of $\mathrm{NC} 12 \mathrm{C}$ were larger than on other peanut lines examined (data not shown).

\section{DISCUSSION}

In this study, leaflets and pegs showed similar susceptibility to colonization by $S$. minor. Leaflets and pegs contain less lignified tissue than lateral branches and main stems $(35,36)$. Parts detached from the partially resistant lines NC-GP WS12 and N96076L were susceptible to the fungus, but lesions expanded more slowly on leaflets, pegs, lateral stems, and main stems of N96076L compared with the susceptible cvs. NC 7 and NC 12C. Differences were less marked on NC-GP WS12, which is a breeding line originally derived from a wild species cross (32). This line has relatively short, woody stems and is less typical of commercial cultivars than N96076L, which was used in subsequent tests.
In detached plant-part inoculations, lateral branches initially were more resistant to infection than pegs. However, lesion counts in the field were observed to be much greater on lateral branches than on pegs (31). Pegs may be able to avoid infection because the surface area (circumference) of a peg is much less than that of other plant parts. Thus, the likelihood of an individual peg contacting a sclerotium in the field is low. Likewise, in more upright plant types, fewer lateral branches touch the soil, possibly limiting plant infection. For this reason, lines must be evaluated in the field to determine whether other mechanisms of resistance or avoidance complement physiological resistance. However, our results demonstrate that resistance expression in the lines tested was stable across soil moisture and temperature.

Several investigators have used the rate of lesion development on detached plant parts to assess resistance to $S$. minor in peanut $(4,6,14,19,21)$. Leaflet inoculations are an easy, clean, quick, and straightforward tool for characterizing resistance and isolate aggressiveness $(14,19)$. Inocula- tions of excised leaves also have been used successfully in crops such as alfalfa (28) and soybean $(13,17)$.

Optimal sclerotial germination of our peanut isolate of $S$. minor at $30^{\circ} \mathrm{C}$ and $\Psi_{\mathrm{M}}$ of $-7.2 \mathrm{kPa}$ differed from reports for isolates of $S$. minor from other hosts and geographic areas. In a recent study of sclerotia from isolates of $S$. minor from Lactuca spp. in California, optimal temperature and $\Psi_{\mathrm{M}}$ were $15^{\circ} \mathrm{C}$ and $-100 \mathrm{kPa}$, respectively (10). We provided a stimulant to germination (acetone), which resulted in up to $90 \%$ germination after 10 days of incubation. In the lettuce isolate research, germination in the absence of a stimulant took up to 12 weeks. The discrepancy in optimal germination conditions also could be explained by isolate differences in the two studies. The California isolates may be adapted to the cool, mild environment typical of the Salinas Valley production area. These conditions contrast markedly with the hot and humid conditions typical of North Carolina peanut-production areas.

Optimal temperatures for colony growth and parasitism of peanut leaflets on the
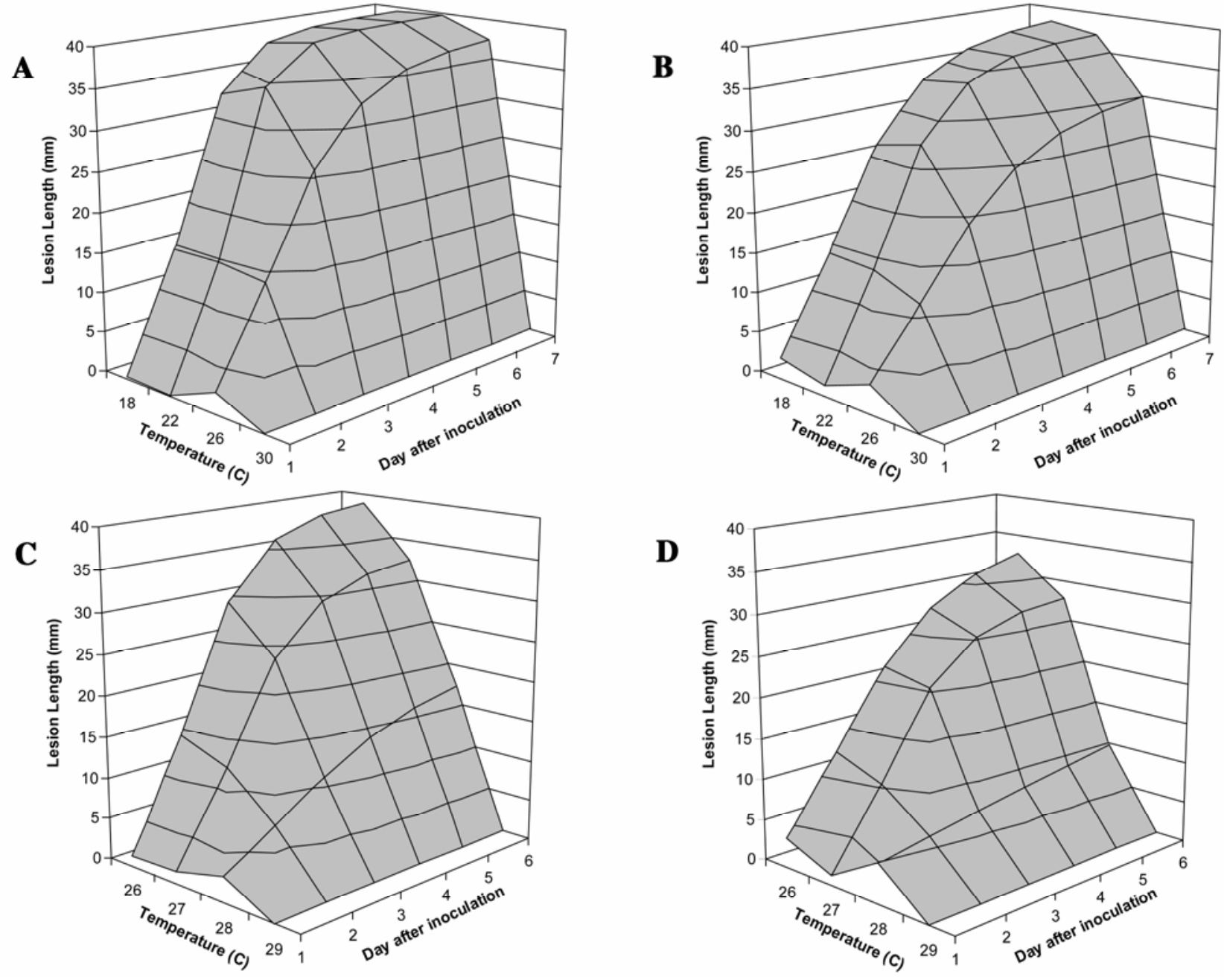

Fig. 5. Lesion expansion on leaflets inoculated with Sclerotinia minor and exposed to four temperatures over time. Average lesion lengths for A, susceptible cvs. NC 7 and NC 12C and $\mathbf{B}$, the resistant breeding line N96076L as described by the equation $L^{\prime}(T, D)=L_{\max }(T) \exp (-\exp [-k(T)(D-2)])$ for temperatures between 18 and $30^{\circ} \mathrm{C}$ for 7 days. Average lesion lengths for $\mathbf{C}$, the susceptible cv. NC 12C and D, the resistant cv. Perry and breeding line N96076L as described by the equation $L^{\prime}(T, D)=L_{\max }(T) \exp (-\exp [-k(T)(D-2)])$ for temperatures between 26 and $29^{\circ} \mathrm{C}$ for 6 days. 
surface of soil were 18 and $22^{\circ} \mathrm{C}$. Lesion development did not occur at 29 or $30^{\circ} \mathrm{C}$. When inoculated leaflets were moved from a high temperature $\left(29^{\circ} \mathrm{C}\right)$ to a low temperature $\left(18\right.$ or $\left.22^{\circ} \mathrm{C}\right)$, lesions developed at the lower temperature. This indicates that the fungus was not killed but was incapable of producing lesions on leaflets at extreme temperatures. The lack of lesion development and colonization of leaflets at high temperatures could be linked to the lack of oxalic acid production and reduced mycelial growth at those temperatures (31). This also may explain the apparently explosive development of disease during cool rainy periods that is often observed in peanut fields. Sclerotia may germinate in warm, humid weather, creating a reservoir of semi-dormant mycelium. When temperatures cool and the environment becomes favorable for mycelial growth, plant tissue invasion occurs and disease results.

Other studies using peanut isolates of $S$. minor found that temperatures near or slightly higher than $22^{\circ} \mathrm{C}$ were optimal for mycelial growth and sclerotial formation on various agar cultures $(5,34)$. Woodard and Simpson (34) reported that growth on agar culture was optimal at 24 to $26^{\circ} \mathrm{C}$ and that the fungus was "inactivated" at $30^{\circ} \mathrm{C}$. Our research shows that the fungus can survive on leaves for short periods of exposure (2 days) to temperatures that are not favorable for growth and colonization of plant tissue, and resume growth when conditions are again optimal.

No consistent $\Psi_{M}$ effect was observed in our studies when temperatures were held constant. Lack of a response to $\Psi_{\mathrm{M}}$ at temperatures of $\leq 28^{\circ} \mathrm{C}$ may reflect similarities in humidity above the soil surface rather than differences in $\Psi_{\mathrm{M}}$. Relative humidities of $\geq 95 \%$ have been shown to significantly affect germination of sclerotia in the laboratory (5). Furthermore, the largest numbers of viable, infectious sclerotia are found in the top $2 \mathrm{~cm}$ of the plow layer of natural soil (1). Sclerotia in this layer may be completely covered with soil or partially exposed to the atmosphere. In our studies, sclerotia were partially exposed; therefore, the atmosphere immediately above the soil influenced germination of sclerotia. The soil contained in the jars provided enough moisture to the atmosphere to meet or exceed the requirement for $\geq 95 \%$ relative humidity. Therefore, our observations of $\Psi_{\mathrm{M}}$ effects suggest that sclerotial germination, mycelial growth, and tissue colonization probably respond to atmospheric relative humidity at the soil surface rather than soil moisture per se.

These studies provide new insights into the effects of soil moisture and temperature on growth and colonization by $\mathrm{S}$. minor in the peanut pathosystem. Breeding strategies should focus on selecting for plants with physiological resistance in pegs, leaves, and other tissues that typically are in contact with the soil surface.
Management strategies may need adjustment in order to focus on protecting pegs, stems, and leaves from infection by $S$. minor. Fungicidal sprays should be focused on protecting parts low in the canopy (especially parts touching the soil surface) through adjustments to nozzle heights or increased spray volume. Bailey and Brune (2) showed that pruning the plant canopy changed the microclimate near the soil and helped to reduce levels of disease. Minor pruning or thinning of the canopy also may help promote fungicide coverage of plant parts in contact with the soil while not having a significant effect on yield.

More precise characterization of the effects of soil moisture and temperature on

Table 2. Mean squares and $F$ values from an analysis of variance for the effects of run (RN), replicate (RP), initial temperature (InT), final temperature (FT), soil matric potential (M), and plant line (L) on lesion size on peanut leaflets inoculated with Sclerotinia minor ${ }^{\mathrm{a}}$

\begin{tabular}{|c|c|c|c|}
\hline Source & df & Mean squares & $F$ value \\
\hline RN & 1 & 2,021 & $1.87 \mathrm{~ns}$ \\
\hline $\mathrm{RP}(\mathrm{RN})$ & 6 & 1,083 & $18.07 * *$ \\
\hline In T & 1 & 29,172 & $103.79 * *$ \\
\hline $\mathrm{RN} \times \operatorname{InT}$ & 1 & 90 & $0.32 \mathrm{~ns}$ \\
\hline FT & 1 & 3 & $0.03 \mathrm{~ns}$ \\
\hline $\mathrm{FT} \times \mathrm{InT}$ & 1 & 57 & $0.56 \mathrm{~ns}$ \\
\hline $\mathrm{RN} \times \mathrm{FT}$ & 1 & 81 & $0.79 \mathrm{~ns}$ \\
\hline $\mathrm{RN} \times \mathrm{FT} \times \mathrm{InT}$ & 1 & 51 & $0.51 \mathrm{~ns}$ \\
\hline M & 2 & 469 & $6.60 * *$ \\
\hline $\mathrm{M} \times \mathrm{InT}$ & 2 & 440 & $6.20 * *$ \\
\hline $\mathrm{M} \times \mathrm{FT}$ & 2 & 33 & $0.46 \mathrm{~ns}$ \\
\hline $\mathrm{RN} \times \mathrm{M}$ & 2 & 72 & $1.01 \mathrm{~ns}$ \\
\hline $\mathrm{M} \times \mathrm{InT} \times \mathrm{FT}$ & 2 & 77 & $1.08 \mathrm{~ns}$ \\
\hline $\mathrm{RN} \times \operatorname{InT} \times \mathrm{M}$ & 2 & 244 & $3.43 *$ \\
\hline $\mathrm{RN} \times \mathrm{FT} \times \mathrm{M}$ & 2 & 27 & $0.38 \mathrm{~ns}$ \\
\hline $\mathrm{RN} \times \mathrm{InT} \times \mathrm{FT} \times \mathrm{M}$ & 2 & 71 & $1.00 \mathrm{~ns}$ \\
\hline $\mathrm{L}$ & 2 & 548 & $9.14 * *$ \\
\hline $\mathrm{L} \times \mathrm{InT}$ & 2 & 33 & $0.55 \mathrm{~ns}$ \\
\hline $\mathrm{L} \times \mathrm{FT}$ & 2 & 189 & $3.15^{*}$ \\
\hline $\mathrm{L} \times \mathrm{M}$ & 4 & 51 & $0.84 \mathrm{~ns}$ \\
\hline $\mathrm{RN} \times \mathrm{L}$ & 2 & 193 & $3.22 *$ \\
\hline $\mathrm{L} \times \mathrm{InT} \times \mathrm{FT}$ & 2 & 48 & $0.80 \mathrm{~ns}$ \\
\hline $\mathrm{L} \times \operatorname{InT} \times \mathrm{M}$ & 4 & 121 & $2.01 \mathrm{~ns}$ \\
\hline $\mathrm{L} \times \mathrm{FT} \times \mathrm{M}$ & 4 & 46 & $0.77 \mathrm{~ns}$ \\
\hline $\mathrm{RN} \times \mathrm{L} \times \mathrm{InT}$ & 2 & 76 & $1.27 \mathrm{~ns}$ \\
\hline $\mathrm{RN} \times \mathrm{L} \times \mathrm{FT}$ & 2 & 52 & $0.86 \mathrm{~ns}$ \\
\hline $\mathrm{RN} \times \mathrm{L} \times \mathrm{M}$ & 4 & 183 & $3.05^{*}$ \\
\hline $\mathrm{L} \times \mathrm{InT} \times \mathrm{FT} \times \mathrm{M}$ & 4 & 37 & $0.63 \mathrm{~ns}$ \\
\hline $\mathrm{RN} \times \mathrm{InT} \times \mathrm{FT} \times \mathrm{L}$ & 2 & 7 & $0.12 \mathrm{~ns}$ \\
\hline $\mathrm{RN} \times \mathrm{InT} \times \mathrm{M} \times \mathrm{L}$ & 4 & 52 & $0.87 \mathrm{~ns}$ \\
\hline $\mathrm{RN} \times \mathrm{FT} \times \mathrm{M} \times \mathrm{L}$ & 4 & 56 & $0.94 \mathrm{~ns}$ \\
\hline $\mathrm{RN} \times \mathrm{InT} \times \mathrm{FT} \times \mathrm{M} \times \mathrm{L}$ & 4 & 72 & $1.21 \mathrm{~ns}$ \\
\hline
\end{tabular}

${ }^{\text {a }}$ Leaflets were exposed to 28 or $29^{\circ} \mathrm{C}$ for 2 days (InT) and then moved to 18 or $22^{\circ} \mathrm{C}$ for 4 days (FT); ** = significance at the $P \leq 0.01$ level; $*=$ significance at the $P \leq 0.05$ level; and ns $=$ not significant at the $P \leq 0.05$ level.

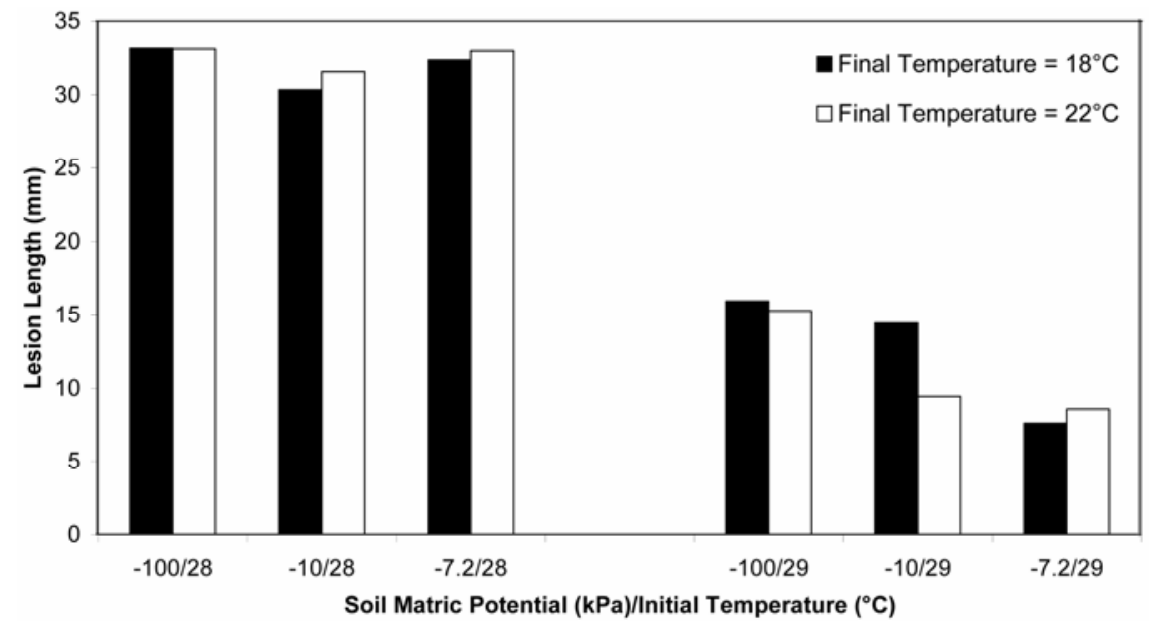

Fig. 6. Lesion length after 6 days when leaflets were incubated at 28 or $29^{\circ} \mathrm{C}$ for 2 days and then moved to 18 or $22^{\circ} \mathrm{C}$ for an additional 4 days. Inoculated leaflets were placed on the surface of soil adjusted to a matric potential of $-100,-10$, or $-7.2 \mathrm{kPa}$. Values are averaged over two runs and three peanut lines. 
plant pathogenesis by $S$. minor may provide insight for improvements in prediction models. Amendments to current Sclerotinia blight forecasting models using revised high-temperature optima for sclerotial germination and cooler conditions for growth may improve predictions of disease onset in midsummer months when temperatures are relatively hot, followed by subsequent cooler conditions when disease becomes most severe. Likewise, adjustments for periods of slowed fungal growth would be particularly useful in more accurately predicting disease following the brief periods of unfavorable environmental conditions that are common during the growing season in the VirginiaCarolina production area.

\section{ACKNOWLEDGMENTS}

This research was supported by the National Peanut Board and the North Carolina Peanut Growers' Association. We thank the Southeastern Plant Environment Laboratory for their aid and expertise and M. C. Garrison for outstanding assistance on this project.

\section{LITERATURE CITED}

1. Adams, P. B. 1986. Production of sclerotia of Sclerotinia minor on lettuce in the field and their distribution in soil after disking. Plant Dis. 70:1043-1046.

2. Bailey, J. E., and Brune, P. D. 1997. Effect of crop pruning on Sclerotinia blight of peanut. Plant Dis. 81:990-995.

3. Beute, M. K., and Rodriguez-Kabana, R. 1979. Effect of volatile compounds from remoistened plant tissue on growth and germination of sclerotia of Sclerotium rolfsii. Phytopathology 69:802-805.

4. Brenneman, T. B., Phipps, P. M., and Stipes, R. J. 1988. A rapid method for evaluating genotype resistance, fungicide activity, and isolate pathogenicity of Sclerotinia minor in peanut. Peanut Sci. 15:104-107.

5. Dow, R. L., Porter, D. M., and Powell, N. L. 1988. Effect of environmental factors on Sclerotinia minor and Sclerotinia blight of peanut. Phytopathology 78:672-676.

6. Chappell, G. F., Shew, B. B., Ferguson, J. M., and Beute, M. K. 1995. Mechanisms of resistance to Sclerotinia minor in selected peanut genotypes. Crop Sci. 35:692-696.

7. Coffelt, T. A., and Porter, D. M. 1982. Screening peanuts for resistance to Sclerotinia blight. Plant Dis. 66:385-387.

8. Coffelt, T. A., Porter, D. M., and Mozingo, R. W. 1994. Registration of VA 93B peanut. Crop Sci. 34:1126-1129.

9. Cruickshank, A. W., Cooper, M., and Ryley, M. J. 2002. Peanut resistance to Sclerotinia minor and S. sclerotiorum. Aust. J. Agric. Res. 53:1105-1110.

10. Hao, J. J., Subbarao, K. V., and Duniway, J. M. 2003. Germination of Sclerotinia minor and $S$. sclerotiorum sclerotia under various soil moisture and temperature combinations. Phytopathology 93:443-450.

11. Hau, B., Eisensmith, S. P., and Kranz, J. 1985. Construction of temporal models: II. Simulation of aerial epidemics. Pages 31-65 in: Advances in Plant Pathology, Vol. 3: Mathematical Modelling of Crop Disease. C. A. Gilligan, ed. Academic Press, Inc., London.

12. Hau, F. C., Beute, M. K., and Smith, T. 1982. Effect of soil $\mathrm{pH}$ and volatile stimulants from remoistened peanut leaves on germination of sclerotia of Sclerotinia minor on Arachis hypogaea. Plant Dis. 66:223-224.

13. Hoffman, D. D., Diers, B. W., Hartman, G. L., Nickell, C. D., Nelson, R. L., Pederson, W. L., Cober, E. R., Graef, G. L., Steadman, J. R., Grau, C. R., Nelson, B. D., del Rio, L. E., Helms, T., Anderson, T., Poysa, V., Rajcan, I., and Stienstra, W. C. 2002. Selected soybean plant introductions with partial resistance to Sclerotinia sclerotiorum. Plant Dis. 86:971980.

14. Hollowell, J. E., Shew, B. B, and Isleib, T. G. 2003. Evaluating isolate aggressiveness and host resistance from peanut leaflet inoculations with Sclerotinia minor. Plant Dis. 87:402-406.

15. Isleib, T. G., Rice, P. W., Mozingo, R. W., II, Bailey, J. E., Mozingo, R. W., and Pattee, H. E. 2003. Registration of 'Perry' peanut. Crop Sci. 43:738-739.

16. Islieb, T. G., Rice, P. W., Mozingo, R. W., Copeland, S. C., Graeber, J. B., Shew, B. B., Smith, D. L., Melouk, H., and Stalker, H. T. Registration of N96076L peanut germplasm. Crop Sci. In press.

17. Kim, H. S., Hartman, G. L., Manandhar, J. B., Graef, G. L., Steadman, J. R., and Diers, B. W. 2000. Reaction of soybean cultivars to Sclerotinia stem rot in field, greenhouse, and laboratory evaluations. Crop Sci. 40:665-669.

18. Langston, D. B., Jr., Phipps, P. M., and Stipes, R. J. 2002. An algorithm for predicting outbreaks of Sclerotinia blight of peanut and improving the timing of fungicide sprays. Plant Dis. 86:118-126.

19. Livingstone, D. M., Hampton, J. L., Phipps, P. M., and Grabau, E. A. 2005. Enhancing resistance to Sclerotinia minor in peanut by expressing a barley oxalate oxidase gene. Plant Pathol. 137:1354-1362.

20. Lumsden, R. D. 1979. Histology and physiology of pathogenesis in plant diseases caused by Sclerotinia species. Phytopathology 69:890896.

21. Melouk, H. A., Akem, C. N., and Bowen, C. 1992. A detached shoot technique to evaluate the reaction of peanut genotypes to Sclerotinia minor. Peanut Sci. 19:58-62.

22. Mozingo, R. W., Coffelt, T. A., and Isleib, T.
G. 2000. Registration of 'VA 98R' peanut. Crop Sci. 9:848-850.

23. Pennypacker, B. W., and Risius, M. L. 1999. Environmental sensitivity of soybean cultivar response to Sclerotinia sclerotiorum. Phytopathology 89:618-622.

24. Phipps, P. M. 1995. An assessment of environmental conditions preceding outbreaks of Sclerotinia blight of peanut in Virginia. Peanut Sci. 22:90-93.

25. Porter, D. M., and Melouk, H. M. 1997. Sclerotinia blight. Pages 34-35 in: Compendium of Peanut Diseases, 2nd ed. N. Kokalis-Burelle, D. M. Porter, R. Rodriguez-Kabana, D. H Smith, and P. Subrahmanyam, eds. American Phytopathological Society Press, St. Paul, MN

26. Porter, D. M., Smith, D. H., and RodriguezKabana, R. 1982. Peanut plant diseases. Pages 326-410 in: Peanut Science and Technology. H. E. Pattee and C. T. Young, eds. American Peanut Research and Education Society, Inc., Yoakman, TX.

27. Pratt, R. G. 1996. Screening for resistance to Sclerotinia trifoliorum in alfalfa by inoculation of excised leaf tissue. Phytopathology 86:923928.

28. Pratt, R. G., and Rowe, D. E. 1998. Evaluation of simplified leaf inoculation procedures for identification of quantitative resistance to Sclerotinia trifoliorum in alfalfa seedlings. Plant Dis. 82:1161-1164.

29. Scherm, H., and van Bruggen, A. H. C. 1993. Response surface models for germination and infection of Bremia lactucae, the fungus causing downy mildew of lettuce. Ecol. Model. 65:281-296.

30. Shaner, G., and Finney, R. E. 1977. The effect of nitrogen fertilization on the expression of slow-mildewing resistance in Knox wheat Phytopathology 67:1051-1056.

31. Smith, D. L. 2004. Biology and epidemiology of Sclerotinia minor on peanut (Arachis hypogaea L.). M.S. thesis. North Carolina State University, Raleigh. Published online.

32. Stalker, H. T., Beute, M. K., Shew, B. B., and Isleib, T. G. 2002. Registration of five leaf spot-resistant peanut germplasm lines. Crop Sci. 42:314-316.

33. Thomas, J. F., Downs, R. J., and Saravitz, C. H. 2006. Phytotron procedural manual: For controlled-environment research at the Southeastern Plant Environment Laboratory, North Carolina State University, Raleigh. Published online.

34. Woodward, K. E., and Simpson, C. E. 1993. Characterization of growth and sclerotial production of Sclerotinia minor isolated from peanut in Texas. Plant Dis. 77:576-579.

35. Yarbrough, J. A. 1957. Arachis hypogaea. The seedling, its epicotyl and foliar organs. Am. J. Bot. 44:19-30.

36. Yarbrough, J. A. 1957. Arachis hypogaea. The form and structure of the stem. Am. J. Bot. 44:31-36. 